\title{
Lactococcus lactis autóctono: evaluación del efecto antilisterial y de propiedades sensoriales en quesos tipo Cuartirolo
}

\section{Autochthonous Lactococcus lactis strain: evaluation of antilisterial activity and sensory properties in Cuartirolo cheese}

González Revello, Álvaro (1), Carro, Silvana (1), Cal, Karina (1), Giacaman, Sheila (2), Aldrovandi, Ariel (1) Departamento Ciencia y Tecnología de la Leche, Facultad de Veterinaria, UdelaR - (2) Ejercicio liberal (3) Departamento Ciencia y Tecnología de la Carne, Evaluación Sensorial, Facultad de Veterinaria, UdELAR Contacto: silvana.carro@gmail.com

RECIBIDO: 2/11/2016 - APROBADO: $13 / 12 / 2016$

\begin{abstract}
Resumen
Las bacterias ácido lácticas (BAL) forman parte de la microbiota natural láctea y son componentes de muchos cultivos iniciadores para elaboración quesera. Las BAL pueden presentar actividad antimicrobiana por la producción de diferentes sustancias, entre ellas, péptidos, denominados bacteriocinas, que pueden ser producidas in situ en la tina quesera. Algunas bacteriocinas incluyen en su espectro de acción Listeria monocytogenes, patógeno asociado a alimentos que representa un riesgo para la salud pública. Este trabajo propuso evaluar el efecto antilisterial de una BAL autóctona en quesos tipo Cuartirolo y la modificación de las propiedades sensoriales por su aplicación. El diseño experimental incluyó dos tratamientos (con o sin Lactococcus lactis autóctono). Los quesos de ambos tratamientos se dividieron en dos, el primer lote se inoculó con Listeria innocua y se realizó recuento a las 2 horas y a los 7 y 14 días. El restante se evaluó sensorialmente mediante una técnica sensorial descriptiva. Se comprobó que Lactococcus lactis GU967439 tiene actividad antagonista in vitro contra Listeria innocua y Listeria monocytogenes. También existieron diferencias significativas $(\mathrm{p}<0,05)$ entre los tratamientos en el recuento de Listeria innocua en las muestras de quesos evaluadas. A excepción del sabor salado, las propiedades sensoriales no mostraron diferencias significativas entre tratamientos.

Palabras clave: Bacterias ácido lácticas, Lactococcus lactis, Listeria monocytogenes, bacteriocinas.
\end{abstract}

\begin{abstract}
Acid lactic bacteria (LAB) are part of milk natural microbiota and are components of many starter cultures used in cheese making. The LAB may exhibit antimicrobial activity, based on the production of various substances, among them, peptides called bacteriocins that can be produced in situ in cheese making.

Some bacteriocins include in their spectrum of action Listeria monocytogenes, pathogen associated to food that represents a risk to public health. The aim of this study was to evaluate antilisterial effect of an autochthonous LAB in Cuartirolo cheese and determine if its use altered the sensory properties of that cheese. This experimental design included two treatments: with and without autochthonous Lactococcus lactis. Cheese was divided into two groups, the first one was inoculated with Listeria innocua, making the quantification two hours, seven days and fourteen days later. Regarding sensory evaluation a descriptive sensory technique was used. In this study, Lactococcus lactis GU96743 had an antagonic activity in vitro against Listeria innocua and Listeria monocytogenes. There were also significant differences $(\mathrm{p}<0,05)$ between the treatments in quantification of Listeria innocua in the samples of cheese evaluated. Except for the salty flavor, the sensorial properties did not show differences between treatments. Keywords: Lactic Acid Bacteria, Lactococcus lactis, Listeria monocytogenes, bacteriocin.
\end{abstract}

\section{Introducción}

Las bacterias ácido lácticas (BAL) constituyen parte de la microbiota natural de la leche, son un grupo de microorganismos de gran importancia desde el punto de vista aplicado y son los componentes fundamentales de muchos de los cultivos iniciadores utilizados en la industria alimentaria. Tradicionalmente han sido empleadas empírica o deliberadamente en la elaboración de diversos productos, entre los que se encuentran derivados lácteos como quesos, yogur, 
etcétera. Adicionalmente a su utilización en los productos fermentados, se han desarrollado estudios para incluir algunas BAL en cultivos denominados "bioprotectores". El término "bioconservación" o "bioprotección" se define como la prolongación de la vida útil e incremento de la seguridad sanitaria de los alimentos mediante la microbiota natural o sus metabolitos (Devlieghere, et al., 2004). Estas bacterias tienen un gran potencial para este fin, ya que son seguras para el consumo (status GRAS: "generalmente reconocidas como seguras", otorgado por la Food and Drug AdministrationFDA) y predominan en la microbiota de muchos alimentos.

El principal factor en el que se basa su actividad antimicrobiana es la producción de ácidos (fundamentalmente ácido láctico) con consecuente disminución del $\mathrm{pH}$, a lo que se suma la competencia por nutrientes presentes en el sustrato. Las BAL son capaces también de producir otras sustancias inhibitorias, tales como: acetaldehído, diacetil, metabolitos activos del oxígeno (peróxido de hidrógeno y radicales libres), $\mathrm{CO}_{2}$ y bacteriocinas. Estas últimas son sustancias proteicas de síntesis ribosomal que pueden ser sintetizadas por numerosas bacterias Gram+ y Gram-. Más de 300 tipos diferentes de bacteriocinas se han descripto producidas por: Lactobacilos, Lactococos, Leuconostoc, Pediococos y Enterococos (De Vuyst y Vandamme, 1994; Osuntoki, et al., 2003; García, et al., 2010; Balciunas, et al., 2013)

Diferentes cepas de Lactococcus lactis forman parte de la mayoría de los cultivos iniciadores comerciales de BAL utilizados en la industria láctea para la elaboración de queso y otros productos fermentados. Se han identificado y caracterizado varias cepas de Lactococcus lactis aisladas de distintas fuentes y que producen diferentes bacteriocinas (Ayad, et al., 2004). Así, nisina fue la primera bacteriocina aislada producida por Lactococcus lactis subesp. lactis. Fue descubierta en 1928 luego de observarse que durante la maduración de quesos determinadas cepas de Lactococcus lactis inhibían el crecimiento de bacterias patógenas y que, además, no era perjudicial para la salud (Montville y Chen, 1998). Al momento han sido identificadas cinco variantes naturales de nisina ( $\mathrm{A}, \mathrm{Z}, \mathrm{Q}, \mathrm{U}$ y $\mathrm{F})$. Otros péptidos antimicrobianos producidos por L. lactis incluyen a la Lacticina 481, Lacticina 3147, Lactococcinas mMFII, A (Diplococcina), B, G, M, Q y 972 (Venema, et al., 1995; De Vuyst, et al., 2007; Oppegård, et al., 2007; Trmcic, et al., 2008; Alegría, et al., 2010).

El espectro de acción antimicrobiano de algunas bacteriocinas es amplio e incluye microorganismos patógenos como, por ejemplo, Listeria monocytogenes. Este microorganismo es un patógeno alimentario importante en la industria láctea, ya que es capaz de crecer en refrigeración (Gandhi y Chikindas, 2007). De acuerdo a lo citado por Lundén et al. (2004), los productos lácteos han sido asociados con aproximadamente la mitad de los brotes de listeriosis en Europa.

Actualmente se buscan sistemas combinados de métodos de conservación para la obtención de alimentos seguros, lo que reduce las concentraciones de aditivos químicos y/o de la intensidad de los tratamientos tecnológicos aplicados (Chen y Hoover, 2003). En este sentido, las bacteriocinas presentan determinadas características que las hacen atractivas para su empleo como bioconservantes, como su naturaleza peptídica, con la consecuente degradación por enzimas digestivas, y resultan inocuas para el consumidor y su microbiota intestinal (Martínez, 1996). Sin embargo, antes de utilizar una BAL productora de bacteriocina como biopreservador es necesario estudiar su eficacia y las concentraciones para lograr un eficien- te control de patógenos responsables de Enfermedades Transmitidas por Alimentos (ETA). También es primordial evaluar la capacidad de la cepa para su crecimiento y producción de bacteriocina en la matriz alimentaria estudiada (Ananou, et al., 2005). Desde hace un tiempo se desarrollan estudios basados en la aplicación de BAL autóctonas como starter o adjunto en elaboración de diversas variedades de quesos para verificar su poder antilisterial (Alegría, et al., 2010; Mendonça, et al., 2010; Hartmann, et al., 2011; Dal Bello, et al., 2012).

Por otra parte, las BAL juegan un rol relevante en la elaboración de quesos, incrementando la diversidad de sabores y texturas. Es importante señalar que las BAL nativas pueden caracterizar el queso de una región geográfica (Albenzio, et al., 2001; Wouters, et al., 2002; Randazzo, et al., 2009). En quesos tradicionales la adición de cepas bacterianas que no forman parte de la microbiota autóctona puede influir negativamente en las propiedades sensoriales de estos productos. Por lo tanto, las cepas bacteriocinogénicas apropiadas para ser utilizadas como bioprotectores deberían provenir de la microbiota autóctona (Trmcic, et al., 2008).

Actualmente, en el Departamento de Ciencia y Tecnología de la Leche de la Facultad de Veterinaria, UdelaR, existe una línea de investigación en esta temática. Se cuenta con cepas nativas con potencial bacteriocinogénico, obtenidas a partir de muestras de leche y quesos artesanales de la zona de Colonia, Uruguay, entre las que se encuentra Lactococcus lactis autóctono GU967439 (Fraga, et al., 2013). Así, en el presente trabajo se propuso evaluar el efecto antilisterial y las propiedades sensoriales en quesos tipo Cuartirolo elaborados con Lactococcus lactis autóctono productor de bacteriocinas como cultivo adjunto.

\section{Materiales y Métodos}

El desarrollo de este trabajo tuvo lugar en el Departamento de Ciencia y Tecnología de la Leche de Facultad de Veterinaria, UDELAR. Los quesos experimentales se elaboraron en la planta piloto del Laboratorio Tecnológico del Uruguay (LATU) y el estudio de las características sensoriales en el Departamento de Productos Lácteos, Cárnicos, Hortifrutícolas y de la Colmena (LACAM) del LATU.

\section{Diseño experimental}

Se realizaron dos repeticiones de las elaboraciones de quesos. En cada una de ellas se utilizaron dos tratamientos: quesos elaborados con L. lactis autóctono $\left(2.5 \times 10^{10} \mathrm{ufc} / \mathrm{g}\right)$ como cultivo adjunto (al que se denominó T1 o Queso Lactis: QL) y el tratamiento control donde no se lo incluyó (llamado: T2 o Queso Control: QC). La subdivisión de los lotes para la evaluación del efecto antilisterial (L. innocua en una concentración: $10^{3} \mathrm{ufc} / \mathrm{g}$ ), detección in vitro de actividad bacteriocinogénica y evaluación sensorial de los quesos se indican en la Figura 1. Todos los ensayos fueron realizados por duplicado siguiendo el mismo proceso de elaboración.

\section{Cepas bacterianas, medios de cultivo y condiciones de crecimiento}

Como cultivo starter se utilizó la cepa comercial de Streptococcus thermophilus (Lyofast ST $060^{\circ}$, Sacco, Italia). Se mantuvo almacenado en su envase original a $-20^{\circ} \mathrm{C}$ hasta el 


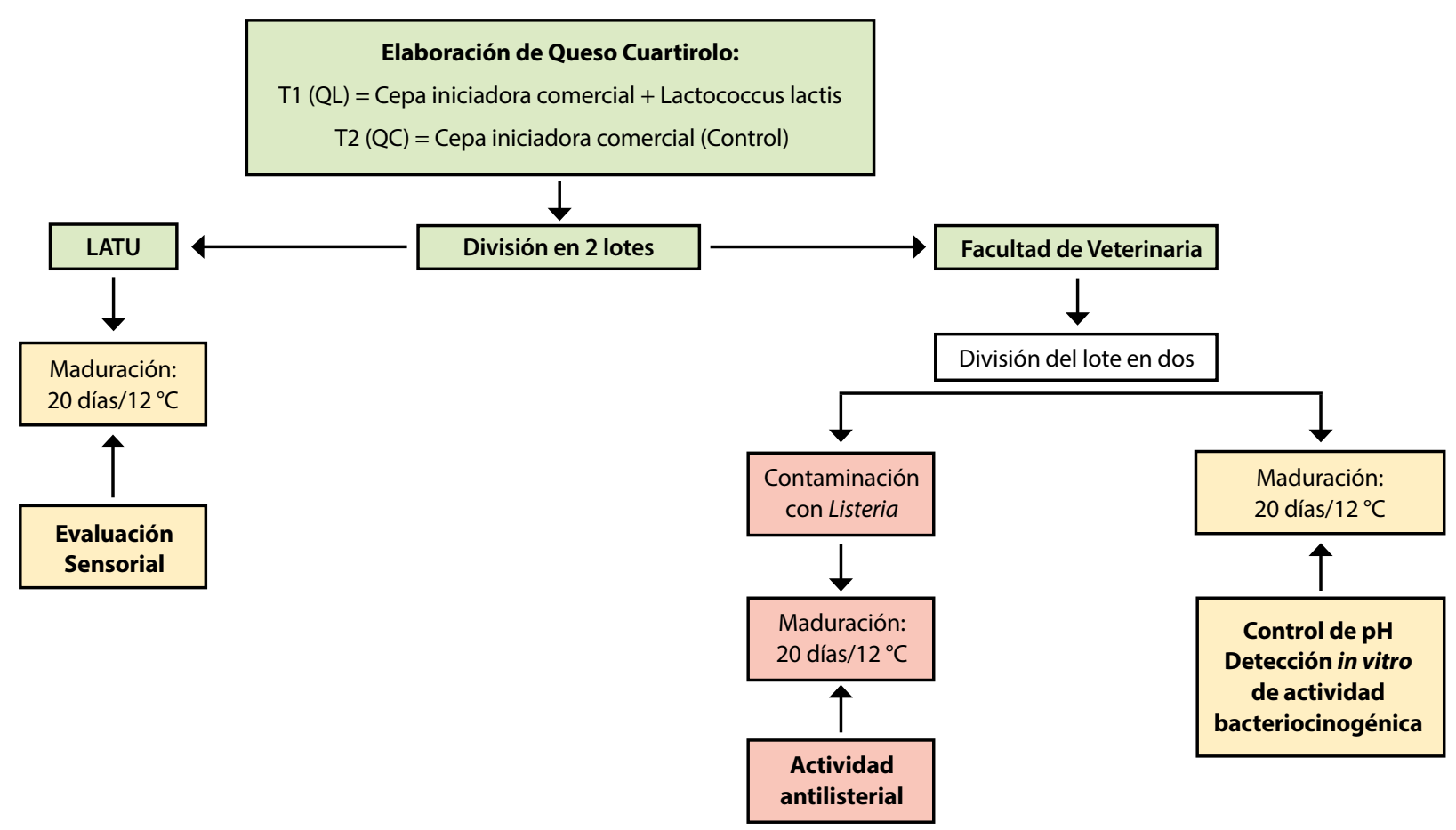

Figura 1. Diseño experimental: tratamientos y división de lotes de queso tipo Cuartirolo para sus posteriores evaluaciones.

momento de su utilización. Como medio de cultivo en los ensayos in vitro se utilizó M17 (Oxoid, UK) suplementado con lactosa (Merck) al 10\% (p/v) incubado a $42{ }^{\circ} \mathrm{C}$ en aerobiosis (Mathot, et al., 2003). A su vez, como cultivo adjunto fue utilizado Lactococcus lactis autóctono GU967439, que presenta comprobado poder bacteriocinogénico y fue aislado de leche cruda utilizada para la elaboración de quesos artesanales en la zona de Colonia (Fraga, et al., 2013). Fue mantenido congelado a $-80^{\circ} \mathrm{C}$ en caldo Man-Rogosa-Sharpe (MRS, Difco, USA) suplementado con glicerol (15\%,v/v). En este caso el medio de cultivo en los ensayos in vitro fue caldo MRS (Difco, USA) incubado a $30^{\circ} \mathrm{C}$ por $48 \mathrm{~h}$ en condiciones de microaerofilia (en jarra provista con una vela) establecidas por ensayos previos en nuestro laboratorio.

Para los ensayos de inhibición in vitro se utilizó el método "well difussion" (Fraga, et al., 2008) con los indicadores: Listeria innocua (ATCC 33090) y Listeria monocytogenes (ATCC 19111). Brevemente, para el crecimiento de estos microorganismos se utilizó caldo infusión cerebro corazón (BHI HiMedia $^{\oplus}$, India) suplementado con $0,6 \%(\mathrm{p} / \mathrm{v})$ de extracto de levadura (HiMedia, India) e incubado a $37^{\circ} \mathrm{C}$ por $24 \mathrm{~h}$ en aerobiosis. La evaluación de inhibición in vitro se realizó con $\mathrm{BHI}$ con Agar (1,5\% p/v, HiMedia, India) suplementado con $0,6 \%(\mathrm{p} / \mathrm{v})$ de extracto de levadura (BHIA con extracto de levadura), el cual, una vez inoculado con el indicador correspondiente, se sembró en doble capa en placa de Petri, de acuerdo a las condiciones que se mencionan a continuación, y se incubó a $37^{\circ} \mathrm{C}$ por $24 \mathrm{~h}$ en aerobiosis.

\section{Actividad antimicrobiana in vitro}

Previa aplicación del Lactococcus lactis en la elaboración de los quesos se verificó su capacidad antagónica in vitro, por el método "agar spot test" (Fraga, et al., 2005) utilizando como indicadores Listeria innocua y Listeria monocytogenes. Un volumen de $2,5 \mu \mathrm{L}$ de un cultivo fresco de $L$. lactis fue inoculado (spotted) sobre la superficie de placas con agar MRS (Difco, USA) e incubado a $37^{\circ} \mathrm{C}$ por $24 \mathrm{~h}$ en condiciones de microaerofilia. Se observó el desarrollo de colonias en la gota inoculada, luego se cubrió la superficie de la placa con BHI soft agar $(0,8 \%)$, inoculado previamente con las bacterias indicadoras citadas en una concentración de $1 \times 10^{8} \mathrm{ufc} / \mathrm{mL}$. Las placas se incubaron a $37^{\circ} \mathrm{C}$ por $24 \mathrm{~h}$ en condiciones de aerobiosis. La inhibición del crecimiento bacteriano se determinó midiendo la zona de inhibición (halo) alrededor de las colonias que crecieron en la gota.

Para evaluar la naturaleza bioquímica de la/s sustancia/s antimicrobiana/s fue obtenido un sobrenadante libre de células (SLC) a partir de un cultivo de $48 \mathrm{~h}$ de L. lactis $\left(10^{8}\right.$ ufc/mL), mediante centrifugación a 10000 RPM, 15 minutos a $4{ }^{\circ} \mathrm{C}$. Alícuotas de este sobrenadante fueron posteriormente tratadas con: calor $\left(10\right.$ minutos a $100^{\circ} \mathrm{C}$, neutralización con $\mathrm{NaOH} 1 \mathrm{M}$, catalasa ( $1 \mathrm{mg} / \mathrm{mL}$, Sigma, USA), pepsina (1 mg/ $\mathrm{mL}$, Sigma, USA), proteinasa K (1 mg/mL, Sigma, USA), a-quimiotripsina ( $1 \mathrm{mg} / \mathrm{mL}$, Sigma, USA) y pronasa E ( $1 \mathrm{mg} /$ $\mathrm{mL}$, Sigma, USA) y analizado mediante la técnica "agar well diffusion" (Fraga, et al., 2008). Como control positivo del ensayo se inoculó $100 \mu \mathrm{L}$ de Nisina (Nisaplin', Danisco) en una concentración de $100 \mathrm{mg} / \mathrm{mL}$. Como control negativo se utilizó el mismo volumen de MRS (Difco, USA) neutralizado con $\mathrm{NaOH} 1 \mathrm{M}$. Este ensayo se realizó por duplicado. De forma similar y con la finalidad de descartar actividad antilisterial por la cepa comercial de Streptococcus thermophilus, se evaluó su capacidad antagónica in vitro por el método "agar spot test". Finalmente, para determinar la compatibilidad entre las cepas que se utilizarían en la elaboración de queso se evaluó in vitro la actividad de la bacteriocina producida por L. lactis sobre el cultivo comercial, utilizando el método "agar well diffusion" (Fraga, et al., 2008). 


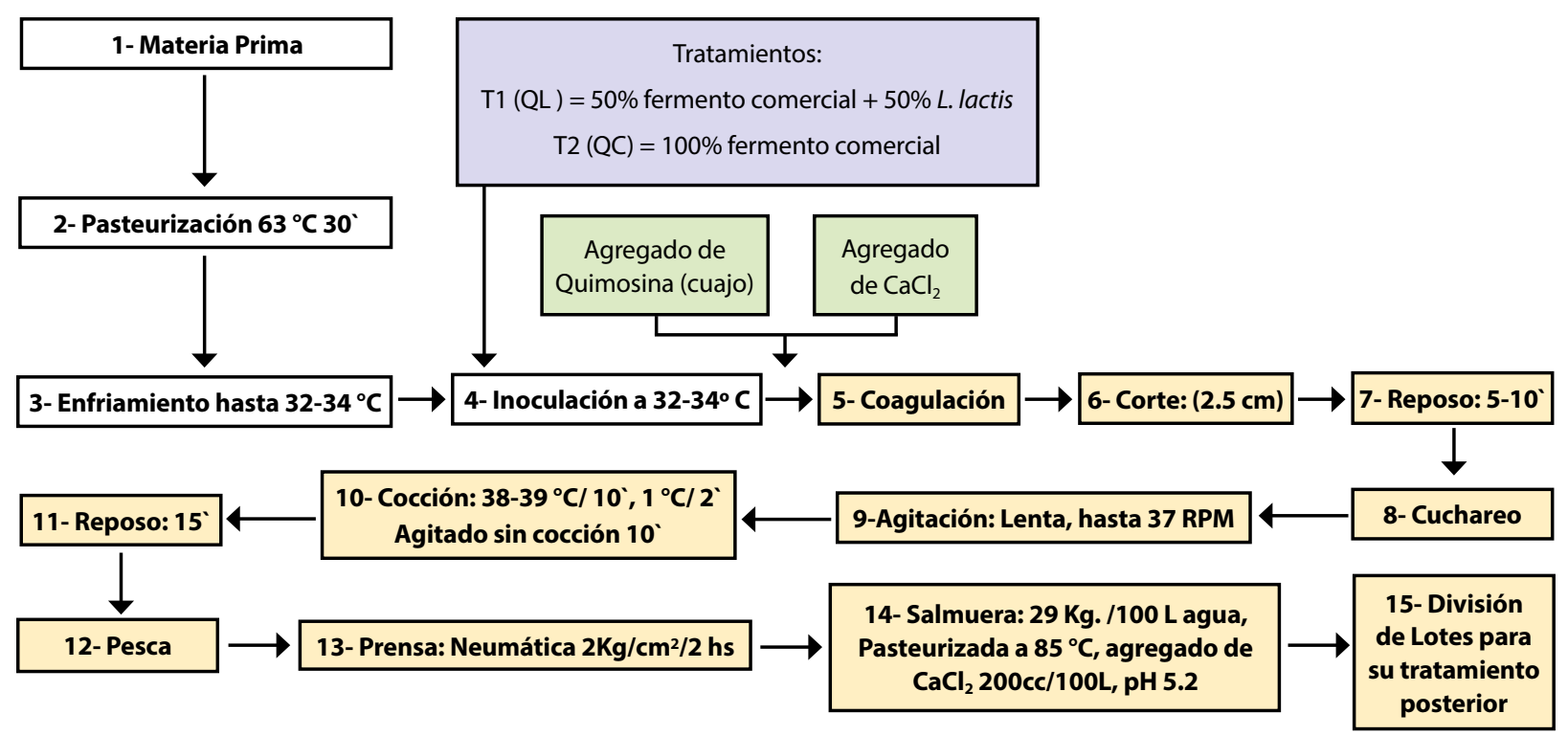

Figura 2. Flujograma general de elaboración de quesos tipo Cuartirolo.

\section{Curva de crecimiento, capacidad de fermentación y efecto inhibitorio de L. lactis en leche}

Mediante curvas de crecimiento se determinó el tiempo para obtener el mayor número de células viables utilizando como matriz leche (reconstituted skim milk - RSM, Conaprole ${ }^{\circledR}$, Uruguay) conforme a lo indicado por Valbuena et al. (2008). Asimismo, se evaluó la capacidad de fermentación estudiando a diferentes tiempos el pH (pH-metro, Oakton pH 5 Acorn series) y la acidez Dörnic (Pinto, et al., 1998). El efecto inhibitorio de L. lactis en leche se evaluó mediante ensayos de "agar well diffusion" con los sobrenadantes neutralizados obtenidos de muestras extraídas a las 12, 24 y $30 \mathrm{~h}$ de crecimiento. El ensayo se realizó por duplicado y la actividad inhibitoria frente a Listeria innocua (ATCC 33090) y Listeria monocytogenes (ATCC 19111), la cual se expresó en $\mathrm{mM}$ midiendo el diámetro del halo de inhibición.

\section{Producción del cultivo \\ de $L$. lactis para su aplicación en la elaboración de quesos}

Se llevó a cabo en un fermentador Bioflo II (New Brunswick Scientific Co., INC. N.J., USA) de $1500 \mathrm{~mL}$ de capacidad operando en modo discontinuo en batch. Como medio de cultivo se utilizó leche en polvo descremada al $10 \%$ esterilizada ( $100{ }^{\circ} \mathrm{C} / 30$ minutos). La fermentación se llevó a cabo en $1100 \mathrm{~mL}$ de leche inoculada al $10 \%$ con un cultivo fresco (aproximadamente $1 \times 10^{8} \mathrm{ufc} / \mathrm{mL}$ ). El cultivo final fue incubado $30^{\circ} \mathrm{C}$ por $15 \mathrm{~h}$ en condiciones de aireación, agitación (40 rpm) y pH libre (la temperatura y el tiempo fueron determinadas de acuerdo a las curvas de crecimiento realizadas anteriormente). Al finalizar la fermentación se determinó la biomasa obtenida mediante recuento en placas con agar MRS. El cultivo fue conservado en fase estacionaria a $5{ }^{\circ} \mathrm{C}$ hasta su utilización en la elaboración de queso tipo Cuarti- rolo. Adicionalmente se tomó una muestra de dicho cultivo para determinar el efecto inhibitorio mediante ensayos de "agar well diffusion". El ensayo se realizó por duplicado y la actividad inhibitoria se expresó en $\mathrm{mM}$ midiendo el diámetro del halo de inhibición.

Previo a la elaboración de los quesos se realizó el ajuste de dosis de los cultivos a utilizar en $40 \mathrm{~L}$ de leche. Para cumplir con el diseño experimental se utilizaron las siguientes dosis para cada tratamiento:

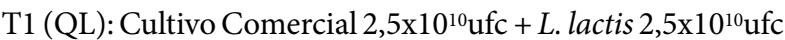
T2 (QC): Cultivo Comercial $5 \times 10^{10}$ ufc

El inóculo del cultivo starter comercial se determinó de acuerdo a la información técnica de la empresa proveedora (Sacco, SRL), mientras que el inóculo del cultivo de L. lactis se calculó de acuerdo a los datos obtenidos anteriormente en el recuento en agar MRS.

\section{Elaboración de queso tipo Cuartirolo}

Se utilizaron un total de $80 \mathrm{~L}$ de leche, que se dividieron en dos lotes de $40 \mathrm{~L}$, uno para cada tratamiento: T1 y T2. La elaboración se realizó de acuerdo al estándar para queso tipo Cuartirolo (Figura 2).

Durante la elaboración de los quesos y luego de su maduración se retiraron muestras para análisis de calidad microbiológica y de composición. Los análisis y técnicas se especifican en la Tabla 1. Entre los análisis se incluyó la detección de Listeria sp. (APHA, 2001) para asegurar además su ausencia antes de inocular los quesos que serían contaminados.

\section{Contaminación con Listeria innocua y cuantificación en diferentes tiempos durante la maduración}

Para la contaminación de los quesos se eligió L. innocua como alternativa a la utilización de L. monocytogenes. Su 


\begin{tabular}{|c|c|c|c|c|}
\hline & Composición & Fisicoquímicos & Microbiológicos & Otros \\
\hline Leche cruda & $\begin{array}{l}\text { Proteína } \\
\text { Materia grasa, } \\
\text { Lactosa } \\
\text { Sólidos totales } \\
(\text { Lactoscan } \\
\left.\text { SLP }^{\circledast}\right)\end{array}$ & $\begin{array}{l}\text { Acidez Dörnic } \\
\text { (Pinto, et al.,1998) } \\
\text { pH (pH-metro, Oakton } \\
\text { pH } 5 \text { Acorn series) } \\
\text { Densidad } \\
\text { Prueba de Alcohol }\end{array}$ & $\begin{array}{l}\text { Mesófilos aerobios totales } \\
\text { Coliformes totales } \\
\text { Staphylococcus coagulasa positiva } \\
\text { (APHA, 2001) }\end{array}$ & $\begin{array}{l}\text { Inhibidores, } \\
\text { Galesloot } \\
\text { (Pinto, et al., 1998) } \\
\text { y Delvotest }{ }^{\oplus} \text { SP-NT } \\
\text { (Stead, et al., 2008) }\end{array}$ \\
\hline $\begin{array}{l}\text { Leche } \\
\text { pasteurizada }\end{array}$ & & & $\begin{array}{l}\text { Mesófilos aerobios totales } \\
\text { Coliformes totales Staphylococcus } \\
\text { coagulasa positiva } \\
\text { (APHA, 2001) }\end{array}$ & $\begin{array}{l}\text { Fosfatasa alcalina } \\
\text { Phosphatesmo MI, } \\
\text { MN }^{\circledR} \\
\text { (Silva, et al., 1997) }\end{array}$ \\
\hline Quesos & $\begin{array}{l}\text { Materia Grasa } \\
\text { Método Van } \\
\text { Gülik (Pinto, } \\
\text { et al., 1998) }\end{array}$ & $\begin{array}{l}\text { pH (pH-metro, Oakton } \\
\text { pH } 5 \text { Acorn series) } \\
\% \text { de humedad } \\
\text { (desecación a peso } \\
\text { constante en balanza } \\
\text { OHAUS }^{\odot} \text {. }\end{array}$ & $\begin{array}{l}\text { Listeria sp. } \\
\text { Salmonella sp. } \\
\text { Staphylococcus coagulasa positiva } \\
\text { Coliformes totales y } \\
\text { termotolerantes }\left(45^{\circ} \mathrm{C}\right) \\
\text { (APHA, 2001) }\end{array}$ & \\
\hline
\end{tabular}

Tabla 1. Análisis de composición, fisicoquímicos y microbiológicos realizados durante la elaboración de quesos experimentales.

uso como sustituto es considerado un modelo adecuado ya descripto por algunos autores (Steg, et al., 1995, citados por Weiss y Hammes, 2005).

Luego de salir de la salmuera los quesos (T1 y T2) se contaminaron con L. innocua por inyección de un inóculo distribuido homogéneamente en todo el queso de manera de obtener $10^{3} \mathrm{ufc} / \mathrm{g}$ en cada queso. Para esto se dividió la superficie de los quesos en cuadrícula y se inyectó cada cuadrante con $500 \mathrm{uL}$ de una suspensión de L. innocua, descargando desde el interior hasta la superficie del queso. El inóculo se obtuvo mediante el crecimiento de L. innocua en BHI por $24 \mathrm{~h}$ a $37^{\circ} \mathrm{C}$ en condiciones de aerobiosis y posteriores diluciones decimales hasta alcanzar dicha concentración.

Para la cuantificación de L. innocua muestras de queso $(10 \mathrm{~g})$ se tomaron por duplicado a las $2 \mathrm{~h}(\mathrm{t} 0), 7$ días (t1) y 14 días (t2) posteriores a la inoculación. El conteo de Listeria $s p$. fue realizado de acuerdo a lo descrito por Rodríguez et al. (2005), mediante la realización de diluciones seriadas y siembra en placas con agar Palcam. Este es un medio selectivo y diferencial para el aislamiento y detección de Listeria monocytogenes y otras especies de Listeria sp. a partir de alimentos. Es recomendado por la American Public Health Association (APHA) para la detección de Listeria monocytogenes en alimentos y por la International Dairy Federation (IDF/FIL) como medio en placa para la detección de las especies de Listeria en leche y productos lácteos (IDF/FIL, 1990; APHA, 2001).

\section{Determinación de $\mathrm{pH}$ y actividad bacteriocinogénica en quesos}

Durante la maduración de los quesos (T1 y T2) mantenidos a $12{ }^{\circ} \mathrm{C}$, se tomaron muestras del lote que no fue contaminado con L. innocua con el fin de determinar variaciones de $\mathrm{pH}$ y actividad bacteriocinogénica in vitro. Las muestras se tomaron en los mismos tiempos que se mencionaron anteriormente y se analizaron por duplicado para la detección de actividad bacte- riocinogénica (Rodríguez, et al., 2005). Resumidamente, muestras de 5 g de cada queso fueron homogenizados con $10 \mathrm{~mL}$ de una solución estéril de $\mathrm{HCl} 0,02 \mathrm{~N}$ a $50^{\circ} \mathrm{C}$. El homogenizado fue centrifugado $\left(12000 \mathrm{~g}, 20 \mathrm{~min}, 4^{\circ} \mathrm{C}\right.$ ) y el sobrenadante obtenido se neutralizó con $\mathrm{NaOH} 1 \mathrm{M}$. Un volumen de $100 \mu \mathrm{L}$ del SLC fue inoculado en pocillos formados en placas con BHIA conteniendo $1 \times 10^{8} \mathrm{ufc} / \mathrm{mL}$ de Listeria innocua. Como control positivo se inoculó con $100 \mu \mathrm{L}$ de Nisina (Nisaplin ${ }^{\circledR}$, Danisco) en una concentración de $100 \mathrm{mg} / \mathrm{mL}$. Como control negativo se utilizó el mismo volumen de MRS (Difco, USA) neutralizado con $\mathrm{NaOH} 1 \mathrm{M}$. Las placas se incubaron a $37^{\circ} \mathrm{C}$ por $24 \mathrm{~h}$ en aerobiosis. Luego de la incubación se midió el diámetro del halo de inhibición del crecimiento y la actividad bacteriocinogénica se expresó en mM.

\section{Evaluación de características sensoriales de los quesos elaborados}

Para establecer si la utilización del cultivo de Lactococcus lactis autóctono como cultivo adjunto afectó las características sensoriales de los quesos en estudio, se aplicó una técnica sensorial descriptiva. Se utilizaron muestras de cada lote de elaboración (aptas para consumo) que fueron maduradas en el LATU a $12^{\circ} \mathrm{C}$. Las mismas fueron evaluadas por un panel entrenado (10 jueces, seleccionados según ISO 22935-1:2009) (Lavanchy, et al., 1993; Bérodier, et al., 1997; Montero, et al., 2005). Se evaluaron las características de textura: dureza manual, dureza en boca, elasticidad, friabilidad, solubilidad, impresión de humedad y adherencia. También se evaluaron los parámetros de sabor: intensidad de olor, intensidad de sabor, dulce, salado, amargo, ácido, picante y retrogusto. Todas ellas se evaluaron con escalas no estructuradas. Cada evaluador midió la intensidad de los 15 atributos para cada muestra de queso y se evaluaron como máximo tres muestras por sesión, realizando dos repeticiones por muestra. En cada sesión se utilizaron muestras de queso comerciales como control. 


\section{Análisis estadístico}

Para evaluar la actividad antilisterial durante la maduración, los resultados de los recuentos en placa se analizaron mediante ANOVA multifactorial considerando los efectos tiempo y tratamiento, utilizando el programa PAST (Hammer, et al., 2001).

Para determinar si la diferencia en las características sensoriales entre los tratamientos era significativa, se realizó para cada atributo una prueba t-Student para muestras independientes con INFOSTAT, V2008.

\section{Resultados}

\section{Actividad antimicrobiana in vitro}

Lactococcus lactis autóctono presentó actividad antimicrobiana in vitro con una media de diámetro de halo de inhibición de $17,5 \pm 0,71 \mathrm{mM}$ y $16,5 \pm 0,71 \mathrm{mM}$ frente a $L$. monocytogenes y $L$. innocua, respectivamente (Figura 3). En cambio Streptococcus Termophilus no presentó actividad antimicrobiana frente a estos indicadores y se descartó que L. lactis inhibiera su crecimiento.

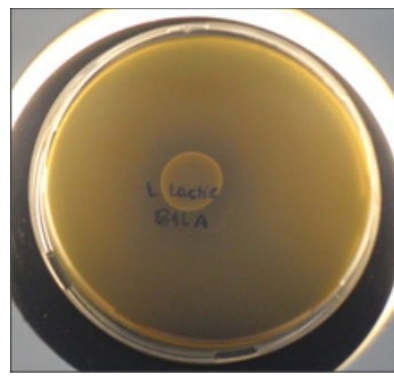

L. innocua

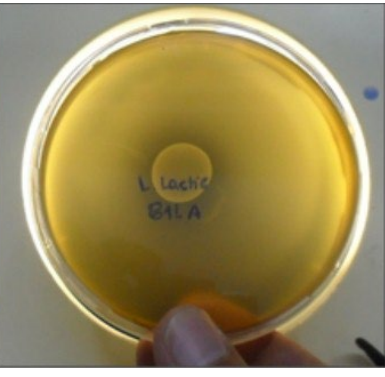

L. monocytogenes
Figura 3. Actividad antagonista de Lactococcus lactis frente a los indicadores L. innocua y L. monocytogenes.

En la Tabla 2 se observan los resultados de la actividad antimicrobiana (frente a L. innocua y L. monocytogenes) en SLC del cultivo de Lactococcus lactis luego de ser sometido a diferentes tratamientos (calor, $\mathrm{pH}$, diferentes enzimas proteolíticas y catalasa). El SLC presentó actividad luego del tratamiento térmico $\left(100^{\circ} \mathrm{C}\right.$ por $\left.10 \mathrm{~min}\right)$ posterior a su neutralización, así como frente al tratamiento con catalasa y pepsina. Por otra parte, no se evidenció efecto inhibitorio luego del tratamiento con $\alpha$-quimotripsina, proteinasa $\mathrm{K}$ y proteasa.

\begin{tabular}{|c|c|}
\hline Tratamiento del sobrenadante & Efecto inhibitorio $^{\mathrm{a}}$ \\
\hline Calor & + \\
$\mathrm{pH}$ & \\
Neutralización & ${ }^{\circ} \mathrm{C}$ por $10 \mathrm{~min}$ \\
Sin neutralización & + \\
Enzimas & + \\
Catalasa & + \\
Pepsina & + \\
a-Qimiotripsina & - \\
Proteasa & - \\
Proteinasa K & - \\
Control + b & + \\
Control - c & - \\
\hline
\end{tabular}

positivo +, PRESENCIA de halo de inhibición, negativo -, AUSENCIA de halo a Efecto inhibitorio sobre Listeria monocytogenes y Listeria innocua b Nisina $100 \mathrm{mg} / \mathrm{mL}$

c MRS estéril y neutralizado

Tabla 2. Efecto in vitro antimicrobiano frente a L. innocua y L. monocytogenes de SLC de Lactococcus lactis sometidos a diferentes tratamientos.

\section{Curva de crecimiento, capacidad de fermentación y efecto inhibitorio de Lactococcus lactis en leche}

La curva de crecimiento y capacidad de fermentación de Lactococcus lactis en leche se muestran en el Gráfico 1. Allí se observa que a las $15 \mathrm{~h}$ de incubación el cultivo alcanzó su máxima concentración bacteriana $\left(10^{8} \mathrm{ufc} / \mathrm{mL}\right)$, encontrán-
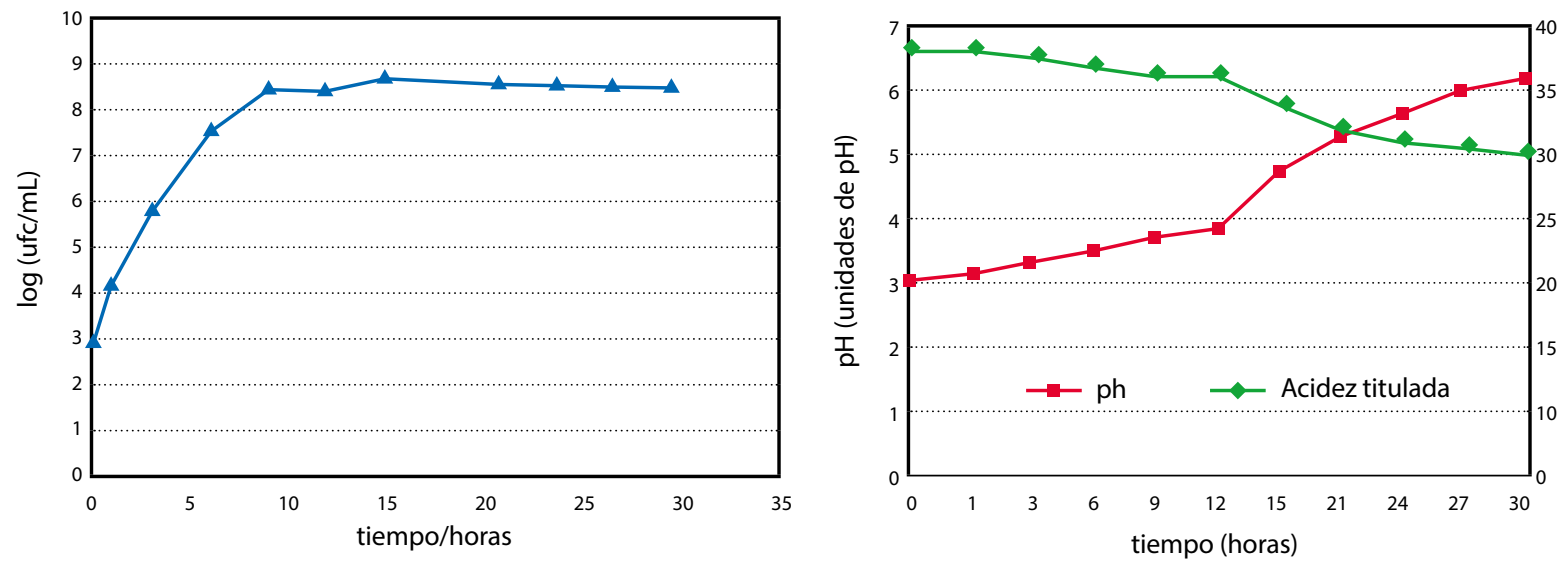

Gráfico 1. Curva de crecimiento (izquierda) y capacidad de fermentación (derecha) de L. lactis cultivado en leche a $30^{\circ} \mathrm{C}$ 
dose en el inicio de la fase estacionaria, momento en el que su $\mathrm{pH}$ era 6,0 y su acidez titulable $20^{\circ} \mathrm{D}$.

Durante su crecimiento en leche los SLC extraídos a las 12,24 y $30 \mathrm{~h}$ de incubación evidenciaron por el método "agar well diffusion" halos de inhibición de: 13,5 $\pm 0,71,15 \pm 1,41$ y $17 \pm 1,41(\mathrm{~mm})$, respectivamente.

En relación a los análisis de leche utilizada en la elaboración (ausencia de fosfatasa alcalina, recuento de mesófilos aerobios y coliformes totales), el proceso de pasteurización fue efectivo y, por tanto, su calidad final adecuada. Asimismo, los análisis de composición (MG y humedad) y microbiológicos de los diferentes lotes de queso tipo Cuartirolo cumplieron con los requisitos establecidos por el Reglamento Bromatológico Nacional (MSP, 1994) (resultados no mostrados). Adicionalmente, la ausencia de Listeria sp. en los quesos antes de su tratamiento permitió validar su cuantificación luego de la contaminación experimental.

\section{Producción del cultivo adjunto de \\ Lactococcus lactis para su aplicación en la elaboración de quesos}

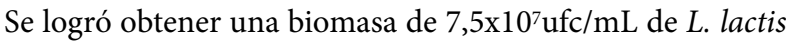
en un volumen de $1100 \mathrm{~mL}$ de leche luego de la incubación a $35^{\circ} \mathrm{C} / 15 \mathrm{~h}$

Por otra parte, se determinó en este cultivo la presencia de efecto inhibitorio sobre L. innocua, obteniendo un halo de inhibición de promedio $15 \pm 1,41 \mathrm{mM}$ de diámetro.

\section{Cuantificación de Listeria innocua durante la maduración de los quesos}

La evolución de la concentración de L. innocua determinada mediante recuento en placa durante la maduración de los quesos se expresa en el Gráfico 2.

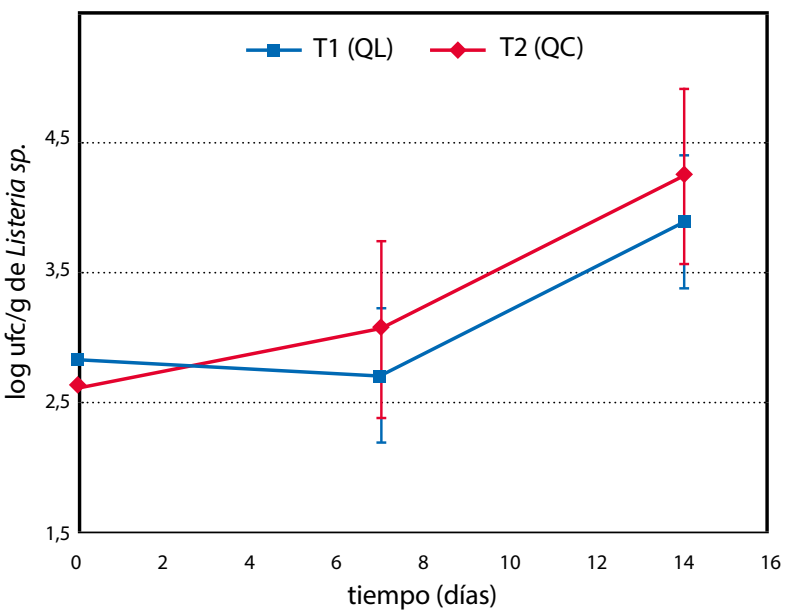

Gráfico 2. Cuantificación de Listeria innocua durante la maduración del queso tipo Cuartirolo almacenado a $12{ }^{\circ} \mathrm{C}$. Queso elaborado con Lactococcus lactis GU967439 (T1) y Queso elaborado con cultivo comercial no bacteriocinogénico (T2).

Los análisis del recuento en placa mediante ANOVA multifactorial en relación al efecto tratamiento evidenciaron diferencias significativas en los recuentos de L. innocua in- dependientemente del tiempo (T1: 3,13 $\pm 0,05 \mathrm{Log}$ ufc/g; T2: $3,3 \pm 0,05 \mathrm{Log}$ ufc/g; $<<0,05)$. Sin embargo, estos resultados difieren en menos de una unidad logarítmica $(0,17 \mathrm{Log} \mathrm{ufc} / \mathrm{g})$.

Los resultados obtenidos en el recuento de L. innocua considerando el efecto tiempo, independientemente del tratamiento, presentaron diferencias significativas a partir de los 14 días, lo que indica que durante los primeros 7 días este crecimiento no es significativo (Tabla 3).

\begin{tabular}{|l|c|c|c|}
\hline & t0 (2 hs) & t1 (7 d) & t2 (14 d) \\
\hline Media (Log ufc/g) & $2,72^{\mathrm{a}}$ & $2,89^{\mathrm{a}}$ & $4,06^{\mathrm{b}}$ \\
Error estándar & 0,06 & 0,06 & 0,06 \\
\hline
\end{tabular}

${ }^{*}$ Letras diferentes (entre pares de datos) indican diferencias significativas con $\mathrm{p}<0,05$.

Tabla 3. Resultado del recuento de L. innocua durante la maduración del queso tipo Cuartirolo (efecto tiempo).

\section{Determinación de $\mathrm{pH}$ y actividad bacteriocinogénica en quesos}

No existieron diferencias significativas $(p<0,05)$ en el $\mathrm{pH}$ durante la maduración de los quesos y la media para ambos tratamientos fue de 5,01 $\pm 0,01$ al final de la maduración. Los resultados de la detección de actividad bacteriocinogénica en los quesos se observan en la Tabla 4 . Si bien el T1 presentó esta actividad (efecto inhibitorio) en los diferentes tiempos evaluados la misma fue disminuyendo y presentó el menor diámetro de halos de inhibición al final de la maduración $(3 \pm 1,41 \mathrm{mM})$.

\begin{tabular}{|l|l|l|l|}
\hline \multirow{2}{*}{} & \multicolumn{3}{|c|}{ Halo de inhibición $(\mathrm{mm})^{\mathrm{a}}$} \\
\cline { 2 - 4 } & $\begin{array}{c}\text { Tiempo } \\
0(2 \mathrm{hs})\end{array}$ & \multicolumn{1}{|c|}{$\begin{array}{c}\text { Tiempo } \\
1 \text { (7 días) }\end{array}$} & $\begin{array}{c}\text { Tiempo 2 } \\
(14 \text { días })\end{array}$ \\
\hline T1 (QL) & $13 \pm 1,41$ & $10 \pm 0$ & $3 \pm 1,41$ \\
T2 (QC) & ND & ND & ND \\
Control + & $21 \pm 0,71$ & $21 \pm 0,71$ & $21 \pm 0,71$ \\
Control - & ND & ND & ND \\
\hline
\end{tabular}

a Valores de la media de los diámetros de los halos de inhibición alrededor del pocillo inoculado \pm SD

b ND- No se detectan halos

Tabla 4. Detección de actividad bacteriocinogénica in vitro en quesos (T1 y T2) durante la maduración.

\section{Comparación de características sensoriales de los quesos elaborados}

Los resultados obtenidos de la evaluación sensorial y su posterior análisis estadístico se observan en la Tabla 6. No se encontraron diferencias significativas entre ambos tratamientos en los atributos evaluados, a excepción del sabor salado. En ese caso la intensidad fue mayor en los quesos elaborados con L. lactis (QL). 


\begin{tabular}{|l|c|c|}
\hline \multirow{2}{*}{ Parámetros sensoriales } & \multicolumn{2}{|c|}{ Tratamientos } \\
\cline { 2 - 3 } & $\mathrm{T} 1(\mathrm{QL})$ & $\mathrm{T} 2(\mathrm{QC})$ \\
\hline Atributos de textura & $3,2^{\mathrm{a}}$ & $3,5^{\mathrm{a}}$ \\
\hline Dureza manual & $2,8^{\mathrm{a}}$ & $3,1^{\mathrm{a}}$ \\
Dureza en boca & $4,6^{\mathrm{a}}$ & $4,6^{\mathrm{a}}$ \\
Elasticidad & $2,8^{\mathrm{a}}$ & $3,0^{\mathrm{a}}$ \\
\hline Friabilidad & $4,2^{\mathrm{a}}$ & $4,2^{\mathrm{a}}$ \\
\hline Solubilidad & $3,9^{\mathrm{a}}$ & $4,0^{\mathrm{a}}$ \\
Impresión de humedad & $3,4^{\mathrm{a}}$ & $3,2^{\mathrm{a}}$ \\
Adherencia & & \\
\hline Atributos de sabor & $2,6^{\mathrm{a}}$ & $2,8^{\mathrm{a}}$ \\
\hline Intensidad de olor & $3,6^{\mathrm{a}}$ & $3,3^{\mathrm{a}}$ \\
Intensidad de sabor & $0,8^{\mathrm{a}}$ & $0,6^{\mathrm{a}}$ \\
Dulce & $3,8^{\mathrm{a}}$ & $3,0^{\mathrm{b}}$ \\
Salado & $1,0^{\mathrm{a}}$ & $1,0^{\mathrm{a}}$ \\
Ácido & $2,0^{\mathrm{a}}$ & $2,0^{\mathrm{a}}$ \\
\hline Picante & $0,5^{\mathrm{a}}$ & $0,5^{\mathrm{a}}$ \\
\hline
\end{tabular}

${ }^{*}$ Letras diferentes (entre pares de datos), indican diferencias significativas con $\mathrm{p}<0,05$.

Tabla 5. Evaluación sensorial de quesos tipo Cuartirolo.

\section{Discusión}

\section{Actividad antimicrobiana in vitro de Lactococcus lactis}

Los resultados de la actividad antimicrobiana in vitro de Lactococcus lactis GU967439 indicaron que presentó actividad antagonista frente a los indicadores $L$. innocua y $L$. monocytogenes, dado que se observó un halo de inhibición al crecimiento de ambos. Estos resultados coinciden con los obtenidos por Bromberg et al. (2005). Esta actividad puede deberse a diferentes factores (producción de ácidos orgánicos, peróxido de hidrógeno e incluso bacteriocinas) por lo que se caracterizó la naturaleza del efecto.

Los resultados indicaron que el SLC de L. lactis GU967439 mantuvo su efecto inhibitorio cuando se aplicó calor, se neutralizó con $\mathrm{NaOH} 1 \mathrm{M}$ y se trató con catalasa y pepsina. La estabilidad térmica es una propiedad común en las bacteriocinas de BAL que tienen bajo peso molecular y estructura poco compleja (probablemente sin estructura terciaria) (Barba y Piard, 1993; González, et al., 1994; Todorov y Dicks, 2005).
A su vez, es una característica primordial que los compuestos utilizados como bioconservantes soporten etapas de calentamiento (pasteurización y esterilización) que son comunes en la industria láctea.

Recientemente, $\mathrm{Lu}$ et al. (2014) han demostrado la termoestabilidad de una bacteriocina producida por $L a c$ tobacillus casei (caseicina $\mathrm{TN}-2$ ) que resistió tratamiento térmico de $121^{\circ} \mathrm{C} / 20 \mathrm{~min}$. Sin embargo, existen algunas bacteriocinas como lactococcina 972, producida por Lactococcus lactis subsp. lactis IPLA 972, cuya termosensibilidad se ha demostrado (Turner, et al., 2013); también helveticina producida por L. helveticus J (Joerger y Klaenhammer, 1986), y lactococcina mMT05 (Ghrairi, et al., 2004), lo cual puede deberse a que poseen mayor tamaño (péptidos superiores a $30 \mathrm{kDa}$ ) y, por tanto, una estructura proteica más compleja.

En la literatura se reporta que las bacteriocinas son generalmente estables a $\mathrm{pH}$ ácido o neutro, aunque existen excepciones. Así, por ejemplo, la solubilidad y estabilidad de la nisina decrece desde un pH óptimo de 2 a un pH de 6 , lo que constituye un inconveniente tecnológico importante para su utilización en los alimentos no ácidos (carne, pescados enlatados y algunos derivados lácteos) (De Vuyst y Vandamme, 1994).

En este trabajo el SLC neutralizado y tratado con catalasa mantuvo la actividad antimicrobiana, lo que descarta que el efecto sea solo por la producción de ácido y peróxido de hidrógeno por parte de Lactococcus lactis. En contraposición, no se observó efecto antimicrobiano cuando el sobrenadante fue tratado con las enzimas a-quimotripsina, proteinasa $\mathrm{K}$ y proteasa.

De acuerdo a la definición de bacteriocinas, la sensibilidad a proteasas es un criterio clave en la caracterización de un inhibidor. Como toda sustancia proteica, generalmente se inactiva por una serie de enzimas proteolíticas (tripsina, a-quimotripsina, pepsina, proteinasa $\mathrm{K}$, etcétera). El comportamiento respecto a la sensibilidad frente a proteasa puede indicar la singularidad de una bacteriocina, ya que este tipo de sustancias de distintas bacterias varían en sensibilidad con diferentes enzimas proteolíticas (De Vuyst y Vandamme, 1994); es posible que la actividad antimicrobiana encontrada se deba también a la presencia de una o varias sustancias peptídicas.

Ortolani et al. (2010) caracterizaron la producción de bacteriocinas y sustancias similares de aislamientos de BAL provenientes de leche cruda y quesos blandos. En sus resultados indican que 18 correspondieron a Lactococcus lactis ssp. lactis, encontrándose en siete de ellos la presencia de genes que codifican para nisina. Como ya se mencionó esta es una bacteriocina de bajo peso molecular, producida por Lactococcus lactis subsp. lactis, que se caracteriza por la presencia de aminoácidos inusuales (lantionina y metil-lantionina) que son los responsables de propiedades funcionales como la tolerancia a la acidez, termoestabilidad a bajo $\mathrm{pH}$ y específica acción bactericida (Stiles, 1993). Comportamiento similar presenta también la Lacticina 481 (De Vuyst y Vandamme, 1994). Por otra parte, la nisina se inactiva con $\alpha$-quimotripsina, pero mantiene su actividad luego del tratamiento con pepsina (De Vuyst y Vandamme, 1994), lo cual coincide con el comportamiento frente a estas enzimas que se observó en este trabajo. Por lo anterior podría inferirse que existe la producción de nisina por L. lactis GU967439, aunque son necesarios estudios complementarios para el aislamiento, purificación y caracterización molecular con la determinación de secuencia de genes de la/s bacteriocina/s. 


\section{Curva de crecimiento en leche: capacidad de fermentación y efecto inhibitorio de Lactococcus lactis}

Los resultados obtenidos en la curva de crecimiento en leche mostraron que el número máximo de células viables se obtuvo a las $15 \mathrm{~h}$ de incubación $(8,72 \mathrm{log} \mathrm{ufc} / \mathrm{mL})$. Ese período se correspondería con el inicio de la fase estacionaria para este microorganismo.

La literatura indica que la biosíntesis de bacteriocinas y particularmente la nisina se desarrolla al final de la fase exponencial (Juncioni de Arauz, et al., 2009), por lo que se definió ese tiempo para la producción del cultivo a aplicar posteriormente en la elaboración del queso. De esa forma el inóculo de Lactococcus lactis repicado nuevamente en leche continuará en esa fase de crecimiento y produciendo la o las sustancias con actividad antimicrobiana. Además, lo antedicho se verifica también por los valores de $\mathrm{pH}$ y acidez en ese período. En las condiciones experimentales ensayadas, fue posible determinar la capacidad de fermentación para el cultivo y expresarla como una relación entre temperatura, tiempo y $\mathrm{pH}$, que fue de $35^{\circ} \mathrm{C} / 15$ horas $/ 5,8$, respectivamente.

El estudio realizado por Martínez (1996), utilizando L. lactis subsp. lactis IPLA 729, indica valores máximos de crecimiento ( $\mathrm{ufc} / \mathrm{mL}$ ) que coinciden con la producción máxima de nisina medida en unidades arbritarias (UA)/mL, cercanos a las 10 horas de incubación tanto en leche como en medio de cultivo M17. En este estudio se pudo observar en relación a la curva de crecimiento en leche que existió actividad antilisterial en todos los tiempos evaluados, lo que parece indicar que se mantiene incluso en la fase estacionaria del crecimiento de la bacteria.

\section{Efecto antilisterial durante la maduración del queso tipo Cuartirolo}

En cuanto al recuento de Listeria innocua durante la maduración, se observa que existieron diferencias significativas entre ambos tratamientos. Durante los primeros siete días la concentración de L. innocua disminuyó en los quesos elaborados con L. lactis ( $0,10 \mathrm{Log}$ ufc/g) en comparación con la dosis inicial. Sin embargo, a partir del día siete de maduración el comportamiento fue similar en ambos tratamientos, alcanzando a los 14 días una concentración superior a 3 Log ufc/g en ambos. Lo anterior coincide con lo reportado por Sulzer y Busse (1991) en un trabajo sobre maduración de quesos Camembert, quienes hallaron que el crecimiento de L. monocytogenes (SLCC 1694) no se vio afectado cuando se utilizó como cultivo adjunto Lactococcus lactis 1881 (productor de nisina) en una concentración de $10^{7} \mathrm{ufc} / \mathrm{g}$. Sin embargo, reportan que el crecimiento de L. monocytogenes fue completamente detenido cuando se lo utilizó como único starter. No obstante, existen estudios que han demostrado la habilidad de bacteriocinas, especialmente nisina, para inhibir el crecimiento de L. monocytogenes en alimentos (Ryser, 1999; Samelis, et al., 2003; Rodríguez, et al., 2005). Altos niveles de esta bacteriocina han corroborado su efecto contra $L$. monocytogenes en quesos blandos en períodos tan cortos como 24 h (Ryser, 1999). Asimismo, Cosentino et al. (2012) comprobaron el efecto contra Listeria de seis Lactococcus lactis subsp. lactis aislados de alimentos lácteos artesanales en Italia. En sus resultados indican una reducción de 4 log de ufc/mL en comparación con el control y 2 log de ufc/mL respecto al inóculo inicial de L. monocytogenes.

\section{Actividad bacteriocinogénica de Lactococcus lactis en quesos}

En relación a la actividad bacteriocinogénica, los resultados de este estudio determinaron su existencia en los quesos elaborados con L. lactis (T1) durante toda la maduración. Sin embargo, este efecto fue disminuyendo a lo largo de la actividad (disminución de los diámetros de los halos de inhibición), lo que podría explicarse por una disminución en la concentración de la bacteriocina y, por tanto, en la actividad de la sustancia responsable de ese efecto. Así Kim et al. (1997) señalaron que la producción de nisina es inhibida cuando llega a una alta concentración, aun cuando las células permanecen creciendo en el medio de cultivo. Además, esta reducción en la actividad inhibitoria podría estar relacionada con otros factores como la falta de nutrientes, la degradación de proteínas por peptidasas, la adsorción de la bacteriocina a la célula productora y/o los diferentes efectos sobre la producción debido a pH bajo, (Todorov y Dicks, 2005b; Todorov, et al., 2007; Juncioni de Arauz, et al., 2009 citados por Taheri, et al., 2012). Otro factor importante a considerar es que la bacteriocina presente una baja estabilidad y que la actividad antimicrobiana decaiga rápidamente.

Maisnier-Patin et al. (1992) estudiaron el efecto de inhibición de Listeria monocytogenes por BAL productoras de nisina en quesos Camembert. Estos autores encontraron que la concentración de nisina tanto en la cuajada como en el queso tuvo una producción paralela al desarrollo de L. lactis. Describen que la concentración de nisina fue máxima en la cuajada a las 9 h y luego disminuyó, lentamente durante 9 a $24 \mathrm{~h}$ y drásticamente en la maduración. En presencia de nisina $L$. monocytogenes disminuyó rápidamente entre las 6 a 24 h, a su vez el efecto de inhibición continuó hasta el final de la segunda semana de maduración en el interior de los quesos Camembert, llegando a una reducción de 3,3 log de ufc/g de Listeria con respecto al nivel inicial. No obstante, posteriormente este patógeno volvió a desarrollarse en los quesos, manteniéndose una diferencia de 2,4 log ufc/g entre los quesos elaborados con el cultivo productor de nisina y el control durante la maduración (seis semanas). En general, observaron que la nisina era efectiva cuando se inoculaba la leche destinada a la elaboración de queso, con una concentración de L. monocytogenes entre $10^{1}$ y $10^{3} \mathrm{ufc} /$ $\mathrm{mL}$. No obstante, cabe señalar que algunas propiedades bioquímicas del queso Camembert difieren a las del queso tipo Cuartirolo y podrían explicar el crecimiento posterior de Listeria en esos quesos. Por ejemplo, el pH en queso Camembert (maduración con hongos) se incrementa desde valores iniciales de 4,5 hasta 5,5 y 7,0 a los 15 y 35 días respectivamente (Liu y Puri, 2008). Mientras que en este trabajo los resultados obtenidos para la determinación de $\mathrm{pH}$ indican que los valores se mantuvieron cercanos a 5 en ambos tratamientos (pH inicial: 5,35 y a los 14 días $\mathrm{pH}: 5,0$ ).

Estudios realizados por Dal Bello et al. (2012) sobre el efecto antilisterial de varios Lactococcus lactis autóctonos productores de diferentes bacteriocinas en quesos Cottage indican que el efecto se mantuvo en valores de $\mathrm{pH}: 6,5,5,5$ y 4,5 (aunque la magnitud en ese efecto presentó diferencias significativas de acuerdo a la bacteriocina). Estas variaciones deben ser consideradas en futuros estudios. 


\section{Evaluación sensorial de quesos tipo Cuartirolo}

No se hallaron diferencias significativas entre ambos tratamientos a excepción del sabor salado, que fue mayor en los quesos elaborados con L. lactis autóctono. En este sentido, Garde et al. (2005) reportan que no hubo diferencias significativas en la intensidad de aroma cuando utilizaron una cepa de Lactoccoccus lactis productora de bacteriocina como cultivo adjunto para elaborar quesos tipo Hispano, en comparación con el tratamiento control, lo que coincide con lo obtenido en este estudio. Por otra parte, los atributos de textura no presentaron diferencias significativas entre ambos tratamientos. Este resultado coincide con lo reportado por Ávila et al. (2005), quienes no hallaron diferencias significativas en los atributos de textura, en quesos tipo Hispano elaborados con Lactococcus lactis productor de bacteriocinas.

Con respecto al atributo de sabor salado, si bien el proceso de salmuera fue igual para ambos quesos, posiblemente hubo diferencias en su distribución. Dado que no se determinó el contenido de sal en los quesos no es posible discutir esta variable, la que debería ser considerada en futuros ensayos. No obstante, cabe destacar que el aumento del sabor salado en el queso elaborado con Lactococcus lactis (T1) podría ser un factor (concentración de cloruro de sodio) que interfirió también en el desarrollo de Listeria innocua en el producto.

\section{Conclusiones}

Los resultados de este trabajo permitieron determinar que Lactococcus lactis GU967439 tiene actividad antagonista in vitro frente a Listeria innocua y Listeria monocytogenes, que coincide con una sustancia de naturaleza proteica tipo bacteriocina. Además, la actividad antilisterial de esta cepa se mantuvo durante su crecimiento en leche. Sin embargo, la aplicación del cultivo adjunto de Lactococcus lactis GU967439 en quesos tipo Cuartirolo no resultó efectiva para el control Listeria innocua en todo el periodo evaluado. Por último, la utilización de Lactococcus lactis autóctono en la elaboración de quesos tipo Cuartirolo no modificó las propiedades sensoriales del queso en las condiciones de este trabajo.

\section{Reconocimientos}

$\mathrm{Al}$ equipo humano del laboratorio del Departamento de Ciencia y Tecnología de la Leche por el apoyo en los análisis de laboratorio.

A FPTA (Fondo de promoción y Tecnología Agropecuaria de Uruguay) y a Comisión sectorial de Investigación Científica (CSIC) de UDELAR, por ser las fuentes de financiamiento con las que se viabilizó este estudio.

\section{Referencias}

APHA, 2001. Compendium of methods for microbiological examination of foods. 4a.ed. Washington DC: APHA

Albenzio, M., Corbo, M., Rehman, S., Fox, P., De Angelis, M., Corsetti, A., Sevi, A. y Gobetti, M., 2001. Microbiological and biochemical characteristics of Canestrato Pugliese cheese made from raw milk, pasteurized milk, or by heating the curd in hot whey. En: International Journal of Food Microbiology, 67, pp.35-48.

Alegría, A., Delgado, S., Roces, C., López, B. y Mayo, B., 2010. Bacteriocins produced by wild Lactococcus lactis strains isolated from traditional, starter-free cheeses made of raw milk. En: International Journal of Food Microbiology, 143, pp.61-66.

Ananou, S., Maqueda, M., Martínez-Bueno, M., Gálvez, A. y Valdivia, E., 2005. Control of Staphylococcus aureus in sausages by enterocin AS-48. En: Meat Science, 71, pp.549-556.

Ávila, M., Garde, S., Gaya, P., Medina, M. y Nuñez, M., 2005. Influence of a bacteriocin-producing lactic culture on proteolysis and texture of Hispánico cheese. En: International Dairy Journal, 15, pp.145-153.

Ayad, E.H.E., Nashat, S., El-Sadek, N., Metwaly, H. y El-Soda, M., 2004. Selection of wild lactic acid bacteria isolated from traditional Egyptian dairy products according to production and technological criteria. En: Food Microbiology, 21, pp.715-725.

Balciunas, E. M., Martinez, F. A. C., Todorov, S. D., de Melo Franco, B. D. G., Converti, A., \& de Souza Oliveira, R. P., 2013. Novel biotechnological applications of bacteriocins: a review. En: Food Control, 32, pp.134-142.

Barba, J.L. y Piard, J.C., 1993. Plantaricins S and T, two new bacteriocins produced by Lactobacillus plantarum LPCO10 isolated from a green olive fermentation. En: Applied and Environmental Microbiology, 59, pp.1416-1422.

Bérodier, F., Lavanchy, P., Zannoni, M., Casals, J., Herrero, L. y Adamo, C., 1997. Guide d'Évaluation Olfacto-Gustative des Fromages à Pâte Dure et Semi-dure. En: LebensmittelWissenschaft und Technologie, 30, pp.653-664.

Bromberg, R., Moreno, I., Delboni, R.R., Cintra, H.C. y Oliveira, P.T.C., 2005. Characteristics of the bacteriocin produced by Lactococcus lactis subsp. Cremoris CTC 204 and the effect of this compound on the mesophilic bacteria associated with raw beef. En: World Journal of Microbiology \& Biotechnology, 21, pp.351-358.

Cosentino, S., Fadda, M., Deplano, M., Melis, R., Pomata, R. y Pisano, M.B., 2012. Antilisterial activity of nisin-like bacteriocin-producing Lactococcus lactis subsp. lactis isolated from traditional Sardinian dairy products. En: Journal of Biomedicine and Biotechnology, ID 376428. doi:10.1155/2012/376428

Cruz-Chamorro, L.; Puertollano, M.A.; Puertollano, E.; Álvarez de Cienfuegos, G.; de Pablo, M. 2006. In vitro biological activities of magainin alone or in combination with nisin. En: Peptides 27 (6):1201-1209.

Chen, H. y Hoover, D.G., 2003. Bacteriocins and their food applications. En: Comprehensive Reviews in Food Science and Food Safety, 2, pp.82-100.

Dal Bello, B., Cocolin, L., Zeppa, G., Field, D., Cotter, P. y Hill, C., 2012. Technological characterization of bacteriocin producing Lactococcus lactis strains employed to control Listeria monocytogenes in Cottage cheese. En: International Journal of Food Microbiology, 153, pp.58-65.

Devlieghere, F., Vermeiren, L. y Debevere, J., 2004. New preservation technologies and limitations. En: International Dairy Journal, 14, pp.273-285.

De Vuyst, L. y Leroy, F., 2007. Bacteriocins from lactic acid bacteria: production, purification, and food applications. En: Journal of Molecular Microbiology and Biotechnology, 13, pp.194-199. 
De Vuyst, L. y Vandamme, E., 1994. Bacteriocins of lactic acid bacteria: microbiology, genetics and application. London: Chapman \& Hall, Ltd.

Fraga, M., Perelmuter, K., Delucchi, L., Cidade, E. y Zunino, P., 2008. Vaginal lactic acid bacteria in the mare: evaluation of the probiotic potential of native Lactobacillus spp. and Enterococcus spp. strains. En: Antonie van Leeuwenhoek, 93, pp.71-78.

Fraga, M., Perelmuter, K., Giachaman, S., Zunino, P. y Carro, S., 2013. Antimicrobial properties of lactic acid bacteria isolated from Uruguayan artisan cheese. En: Food Science and Technology, 33, pp.801-804.

Fraga, M., Scavone, P. y Zunino, P., 2005. Preventive and therapeutic administration of an indigenous Lactobacillus sp. strain against Proteus mirabilis ascending urinary tract infection in a mouse model. En: Antonie van Leeuwenhoek, 88, pp.25-34.

Gandhi, M. y Chikindas, M.L., 2007. Listeria: A foodborne pathogen that knows how to survive. En: International Journal of Food Microbiology, 113, pp.1-15.

Garde, M., Ávila, M., Medina, M. y Núñez, M., 2005. Influence of a bacteriocin producing lactic culture on the volatile compounds, odour and aroma of Hispánico cheese. En: International Dairy Journal,15, pp.1034-1043.

González, B., Arca, P., Mayo, B. y Suarez, J.E., 1994. Detection, Purification, and Partial Characterization of plantaricin C, a bacteriocin produces by a Lactobacillus plantarum strain of dairy origin. En: Applied and Environmental Microbiology, 60, pp.2158-2163.

Ghrairi, T., Frere, J., Berjeaud, J.M. y Manai, M., 2004. Lactococcin mMT24, a novel two-peptide bacteriocin produced by Lactococcus lactis isolated from rigouta cheese. En: International Journal of Food Microbiology, 105, pp.389-398.

Hammer, Ø., Harper, D.A. y Ryan, P.D., 2001. PAST: Paleontological statistics software package for education and data analysis. En: Paleontología Electrónica, 4, pp.1-9.

Hartmann, H., Wilke, T. y Erdmann, R., 2011. Efficacy of bacteriocin-containing cellfree culture supernatants from lactic acid bacteria to control Listeria monocytogenes in food. En: International Journal of Food Microbiology, 146, pp.192-199.

International Dairy Federation, 1990. Milk and milk products detection of Listeria monocytogenes. Provisional recommended method 143. Bruselas: IDF.

International Organization for Standardization ISO 229351:2009 (IDF 99-1:2009). Milk and milk products -- Sensory analysis -- Part 1: General guidance for the recruitment, selection, training and monitoring of assessors. Génova: ISO.

Joerger, M. y Klaenhammer, T., 1986. Characterization and purification of helveticin J and evidence for a chromosomally determined bacteriocin produced by Lactobacillus helveticus 481. En: Journal of Bacteriology, 167, pp.439-446.

Juncioni de Arauz, L., Faustino Jozala, A., Gava Mazzola, P. y Vessoni Penna, T., 2009. Nisin biotechnological production and application: a review. En: Trends in Food Science \& Technology, 20, pp.146-154.

Lavanchy, P., Berodier, F., Zannoni, M., Noël, Y., Adamo, C., Squella, J. y Herrero, L., 1993. L'Evaluation Sensorielle de la Texture des Fromages à Pâte Dure ou Semi-Dure. Etude Interlaboratoires. En: Lebensmittel-Wissenschaft und Technologie, 26, pp.59-68.
Lundén, J., Tolvanen, R. y Korkeala, H., 2004. Human Listeriosis Outbreaks Linked to Dairy Products in Europe. En: Journal of Dairy Science, 87, pp.E6-E11.

Lü, X., Hu P., Dang, Y. y Liu, B., 2014. Purification and partial characterization of a novel bacteriocin produced by Lactobacillus casei TN-2 isolated from fermented camel milk (Shubat) of Xinjiang Uygur Autonomous region, China. En: Food Control, 43, pp.276-283.

Maisnier-Patin, S.; Deschamps, N.; Tatini, S.R.; Richard, J., 1992. Inhibition of Listeria monocytogenes in Camembert cheese made with a nisin-producing starter. En: Lait, 72, pp.249-263.

Ministerio de Salud Pública (MSP), 1994. Reglamento Bromatológico Nacional. Decreto $N^{\circ} 315 / 9942^{a}$ ed. Montevideo: IMPO, CD ROM.

Patin, S., Deschamps, N., Tatini, S.R. y Richard, J., 1992. Inhibition of Listeria monocytogenes in Camembert cheese made with a nisin-producing starter. En: Lait, 72, pp.249-263.

Martínez, B., 1996. Bacteriocinas de Lactococcus lactis aislados de quesos asturianos: nisina $z$ y lactococina 972. Asturias: Universidad de Oviedo. (Tesis doctoral)

Mathot, A., Beliard, E. y Thuault, D., 2003. Streptococcus thermophilus 580 Produces a Bacteriocin Potentially Suitable for Inhibition of Clostridium tyrobutyricum in Hard Cheese. En: Journal of Dairy Science, 86, pp.3068-3074.

Mendonça, P., Martins, L., Tassinari, M., Keizo, A., Nogueira, G. y Nero, L., 2010. Protocols for the isolation and detection of lactic acid bacteria with bacteriocinogenic potencial. En: LWT-Food Science and Technology, 43, pp.1320-1324.

Montero, H., Aranibar, G., Cañameras, C. y Castañeda, R., 2005. Metodología para la caracterización de quesos argentinos. En: INTI-Lácteos. En: JASLIS 2005, Argentina (6-8 de septiembre de 2005). Buenos Aires: [s.n.].

Montville, T.J y Chen, Y., 1998. Mechanistic action of pediocin and nisin: recent progress and unresolved question. En: Applied Microbiology and Biotechnology, 50(5), pp.511-9

Oppegård, C., Fimland, G., Thorbæk, L. y Nissen-Meyer, J., 2007. Analysis of the Two-Peptide Bacteriocins Lactococcin $\mathrm{g}$ and Enterocin 1071 by Site-Directed Mutagenesis. En: Applied and Environmental Microbiology, 73, pp.2931-2938.

Ortolani, M.B.T., Moraes, P.M., Perin, L.M., Viçosa, G.N., Carvalho, K.G., Silva Junior, A y Nero, L.A., 2010. Molecular identification of naturally occurring bacteriocinogenic and bacteriocinogenic-like lactic acid bacteria in raw milk and soft cheese. En: Journal of Dairy Science, 93, pp.2880-2886.

Osuntoki, A.A., Gbenle, G.O. y Olukoya, D.K., 2003. Evidence for chromosomal determination of fungicidal activity in strain of Lactobacillus brevis and Lactobacillus fermentum isolated from fermented foods. En: Folia Microbiologica, 48 , pp.56-58.

Pinto, M., Vega y León, M. y Pérez, N., 1998. Métodos de análisis de la leche y derivados. Valdivia: Universidad Austral de Chile.

Randazzo, C., Caggia, C. y Neviani, E., 2009. Application of molecular approaches to study lactic acid bacteria in artisanal cheeses. En: Journal of Microbiology Methods, 78, pp.1-9.

Rodríguez, E., Calzada, J., Arqués, J.L., Rodríguez, J.M., Nuñez, M. y Medina, M., 2005. Antimicrobial activity of pediocin-producing Lactococcus lactis on Listeria monocytogenes, Staphylococcus aureus and Escherichia coli 
O157:H7 in cheese. En: International Dairy Journal, 15, pp.51-57.

Ryser, E.T., 1999. Incidence and behavior of Listeria monocytogenes in cheese and other fermented dairy products. En: Ryser, E.T. y Marth, E.H. (eds.). Listeria, listeriosis and food safety. New York: Marcel Dekker. pp.411-503.

Samelis, J., Kakouri, A., Rogga, K., Savvaidis, I. y Kontominas, M., 2003. Nisin treatments to control Listeria monocytogenes post-processing contamination on Anthotyros, a traditional Greek whey cheese, stored at $4^{\circ} \mathrm{C}$ in vacuum packages. En: Food Microbiology, 20, pp.661-669.

Silva, P., Pereira, D., Oliveira, L. y Costa Junior, L., 1997. FísicoQuímica do leite e derivados. Métodos analíticos. Minas Gerais: Oficina de Impressão Gráfica e Editora Ltda. Juiz de Fora.

Stead, S.L., Ashwin, H., Richmond, S.F., Sharman, M., Langeveld, P.C., Barendse, J.P., Stark, J. y Keely, B.J., 2008. Evaluation and validation according to international standards of the Delvotest ${ }^{\oplus}$ SP-NT screening assay for antimicrobial drugs in milk. En: International Dairy Journal, 18, pp.3-11.

Stiles, M.E., 1993. Bacteriocins produced by Leuconostoc species. En: Journal of Dairy Science, 77, pp.2718-2724.

Sulzer, G. y Busse, M., 1991. Growth inhibition of Listeria spp. on Camembert cheese by bacteria producing inhibitory substances. En: International Journal of Food Microbiology, 14 , pp. $287-296$

Taheri, P., Samadi, N., Ehsani, M.R., Khoshayand, M.R. y Jamalifar, H., 2012. An evaluation and partial characterization of a bacteriocin produced by Lactococcus lactis subsp lactis ST1 isolated from goat milk. En: Brazilian Journal of Microbiology, 43, pp.1452-1462.

Todorov, S.D. y Dicks, L.M.T., 2005. Lactobacillus plantarum isolates from molasses produces bacteriocins active against Gram-Negative bacteria. En: Enzyme and Microbial Technology, 36, pp.318-326.
Todorov, S.D. y Dicks, L.M., 2005b. Optimization of bacteriocin ST311LD production by Enterococcus faecium ST311LD, isolated from spoiled black olives. En: Journal of Microbiology, 43, pp.370-374.

Todorov, S.D., Nyati, H., Meincken, M. y Dicks, L.M., 2007. Partial characterization of bacteriocin AMA-K, produced by Lactobacillus plantarum AMA-K isolated from naturally fermented milk from Zimbabwe. En: Food Control, 18, pp.656-664.

Turner, D., Lamosa, P., Rodríguez, A. y Martínez, B., 2013. Structure and properties of the metastable bacteriocin Lcn972 from Lactococcus lactis. En: Journal of Molecular Structure, 1031, pp.207-210

Trmcic, A., Obermajer, T., Rogelj, I. y Bogovic Matijasic, B., 2008. Short communication: Culture-independent detection of lactic acid bacteria bacteriocin genes in two traditional Slovenian raw milk cheeses and their microbial consortia. En: Journal of Dairy Science, 91, pp.4535-4541.

Valbuena, E., Barreiro, J., Sánchez, E., Castro, G., Kutchinskaya, V. Y Briñez, W., 2008. Predicción del crecimiento de Lactococcus lactis subsp. lactis en leche descremada estéril en función a la temperatura. En: Revista Científica Facultad Ciencias VeterinariasUniversidad de Zulia- Venezuela FCV-LUZ, 18, pp.745-758.

Venema, K., Venema, G. y Kok, J., 1995. Lactococcal bacteriocins: mode of action and immunity. En: Trends in Microbiology, 3, pp.299-304.

Weiss, A. y Hammes, W., 2005 Lactic acid bacteria as protective cultures against Listeria spp. on cold-smoked salmon. En: European Food Research and Technology, 222, pp.343-346.

Wouters, J.T., Ayad, E.H., Hugenholtz, J. y Smit, G., 2002. Microbes from raw milk for fermented dairy products. En: International Dairy Journal, 12, pp.91-109. 